\title{
AMPLIAÇÃO DO ENSINO FUNDAMENTAL PARA NOVE ANOS: entre as normatizações da politica educacional, o movimento teórico e as representações sociais dos profissionais da escola pública*
}

\author{
EXTENDING PRIMARY EDUCATION TO NINE YEARS: among the \\ regulations of the education policy, the theoretical movement, \\ and the social representations of state school professionals
}

\author{
Graziela Zambão Abdian ${ }^{* *}$ \\ Thaís Monteiro Ciardella ${ }^{* * *}$
}

\begin{abstract}
Resumo
O objetivo desse artigo é analisar as representações sociais de grupos de profissionais da educação de duas escolas (municipal e estadual) sobre a política de ampliação do Ensino Fundamental de nove anos. Buscou-se explicitar algumas inter-relações entre a natureza individual e social das representações sociais, e compreender alguns motivos pelos quais a escola pública vem reproduzindo as práticas pedagógicas tradicionais. A pesquisa envolveu entrevista com os diretores e coordenadores das duas unidades escolares. Concluiu-se que os profissionais entrevistados atribuem características positivas à política, entretanto não conhecem as raízes de sua constituição e as razões que a fundamentam; o texto da política apresenta aspectos progressistas, mas as contradições emanadas das diretrizes governamentais acabam por incentivar as práticas historicamente vivenciadas, dificultando a reorganização do trabalho na escola.
\end{abstract}

Palavras-chave: Representações sociais. Ensino fundamental de nove anos. Administração escolar.

\begin{abstract}
This paper aims to analyse the social representations of professional education groups of two schools (a city school and a state one) about the policy of extending primary education to nine years. Some relationships between the individual and social nature of social representations were made clear, and the reasons why public schools have been carry on traditional pedagogical practices were investigated. The research consisted of interviews with the directors and coordinators of both schools. The conclusion was that these professionals attribute positive characteristics to the policy, but they do not know its origins or its bases; the text of the policy presents some progressive aspects, but the contradictions resulted from the government guidelines end up encouraging historically experienced practices, which makes it difficult to reorganise the school work environment.
\end{abstract}

Keywords: Social representations. Nine-year primary education. School management.

\section{Introdução}

O tema apresentado tem origem nas discussões e estudos realizados no grupo de pesquisa ao qual se vincula, que tem na escola e em sua prática diária a expressão dos elementos principais para a realização de estudos em Administração Escolar ${ }^{1}$.

\footnotetext{
"Pesquisa financiada pela Fundação de Amparo à Pesquisa do estado de São Paulo (FAPESP).

" Professora doutora da Universidade Estadual Paulista Júlio de Mesquita Filho (Marília/SP). E-mail: graziela.maia@gmail.com

** Graduanda do curso de Licenciatura em Pedagogia da Universidade Estadual Paulista Júlio de Mesquita Filho, UNESP. E-mail: thaciardella@hotmail.com

1 O Projeto de pesquisa "Formação, função e formas de provimento do cargo de administrador escolar: questões históricas e atuais" (auxílio FAPESP) está vinculado ao Centro de Estudos e Pesquisas em Administração da Educação (CEPAE, Unesp/Marília) e apresenta, entre seus objetivos, a preocupação de trabalhar com o tema, foco de seu estudo, tensionando a literatura da área com as diretrizes da política educacional. Neste sentido, a escola é o centro, ao possibilitar delinear nossas preocupações entre as diretrizes da política e o desenvolvimento teórico da área.
}

Os objetivos principais de uma das pesquisas concluídas em meados de 2010, a qual desencadeou o texto aqui configurado, delinearam-se a partir da necessidade de investigar o processo de implementação de uma política educacional, no caso, a política do Ensino Fundamental de nove anos, sendo eles: realizar análise das representações sociais dos diretores de escola e dos docentes diretamente relacionados à concretização do Ensino Fundamental de nove anos, em duas escolas públicas de um município do interior do estado de São Paulo², uma estadual e outra municipal; identificar as principais dificuldades e êxitos do processo na percepção dos

\footnotetext{
2 O município é de porte médio, com aproximadamente 250.000 habitantes, conta com escolas públicas municipais e estaduais de ensino fundamental, relacionadas, respectivamente, à Secretaria Municipal de Educação (que já constitui sistema próprio) e à Diretoria de Ensino (que é regional e abriga escolas de outros municípios vizinhos). No município também estão presentes vários cursos de formação de professores. Entre eles, destacam-se dois cursos de Pedagogia, um da Universidade Estadual e outro de Universidade particular.
} 
diretores e dos docentes das escolas pesquisadas; diagnosticar como vem sendo organizado o trabalho na escola para a implantação do Ensino Fundamental de nove anos.

A pesquisa contou com o apoio da Fundação de Amparo à Pesquisa do Estado de São Paulo (FAPESP), mediante concessão de bolsa, foi desenvolvida em uma perspectiva qualitativa, valorizando as "[...] experiências e vivências dos indivíduos e grupos que participam e constroem o cotidiano escolar" (ANDRÉ, 2006, p. 37), e privilegiou, como procedimentos metodológicos, a observação e a realização, transcrição e análise de entrevistas semiestruturadas com a equipe de direção e os docentes do primeiro ao quinto ano das duas escolas. Para realizar a escolha das duas escolas tivemos que estabelecer critério: como estamos trabalhando com projeto de pesquisa recente que aborda os indicadores de qualidade e a gestão democrática, optamos por tomar como objeto de investigação duas escolas, uma estadual e outra municipal, que se destacaram nos índices publicizados pelos governos (federal, estadual e municipal) ${ }^{3}$.

Nosso trabalho está inserido no movimento da área que privilegia a escola como objeto de estudo, considerando a especificidade do seu processo de produção pedagógica (PARO, 1986), e procura, mediante subsídios da "abordagem do ciclo de políticas" (BALL; BOWE, 1992 apud MAINARDES, 2006), focalizar as representações sociais dos dois grupos de profissionais da educação sobre a ampliação do Ensino Fundamental para nove anos.

Ao falarmos sobre os estudos da escola, estamos considerando que o movimento teórico de valorização do nível meso de abordagem para as pesquisas em Administração Escolar esteve presente no Brasil e fortemente articulado com as pesquisas em Portugal e em outros países europeus. Em 1996, Barroso organizou um livro que se constitui de palestras referentes ao Simpósio realizado em Portugal em meados dos anos 1990, que abordou especificamente a construção da escola como objeto de estudos.

Para Derouet (1996), há duas razões que contribuíram para a construção do novo objeto de estudo: a evolução endógena da área da Administração Escolar e a evolução das concepções políticas e administrativas que, integradas, indicam a importância de recomposição da área. A que nos interessa, neste momento, é a primeira, que foi marcada, inicialmente, pelos estudos anglo-saxônicos que abordaram a temática no sentido dos "efeitos de escola", priorizando a questão da eficácia e secundarizando aspectos de fundo como, por exemplo, o modo como as políticas públicas são construídas. Derouet

\footnotetext{
${ }^{3} \mathrm{O}$ projeto de pesquisa enunciado é continuidade da pesquisa citada em nota anterior e passou a integrar um grupo de pesquisadores que tiveram o projeto em rede intitulado "Indicadores de qualidade e gestão democrática" aprovado do Edital n. 38/2010 CAPES/INEP.
}

(1996) afirma que os estudos que focalizam as organizações escolares como "cidades a construir" marginalizaram a investigação dos primeiros estudos (os anglo-saxônicos) e passaram a abordar a escola como uma cidade política no sentido de concretização das políticas educativas e, concomitantemente, de exercício de práticas contraditórias e marcadas por conflitos de ideias e interesses individuais e coletivos. No sentido de "cidades a construir" - melhor dizendo, cidades em construção -, pesquisamos a escola e as representações sociais de seus profissionais da educação. O subsídio teórico nos permite dizer que

O ordenamento jurídico-burocrático e as políticas produzem as diretrizes para o modo de existência da escola na condição dos sistemas e redes escolares, das variadas naturezas escolares atualmente existentes. No entanto, as diretrizes não se reproduzem concretamente tal qual são enunciadas e propostas ou mesmo impostas no plano superestrutural. A organização da esfera educacional e de cada instituição escolar é única, mesmo que ela mantenha relações de identidade com outras instituições da mesma natureza. (SILVA JR; FERRETTI, 2004, p. 58).

O estudo valoriza as formas como os sujeitos integrantes da escola se organizam, pensam, compreendem, enfim, representam as realidades circundantes, entre elas as propostas das políticas educacionais. Consideramos, portanto, que

[...] os actores escolares não se limitam ao cumprimento sistemático e integral das regras hierarquicamente estabelecidas por outrém, não jogam apenas um jogo com regras dadas a priori, jogam-no com a capacidade estratégica de aplicarem selectivamente as regras disponíveis e mesmo de inventarem e construírem novas regras. (LIMA, 1998, p. 94, grifos do autor).

Quando valorizamos a escola e seus sujeitos, consideramos suas relações e inter-relações com os diferentes âmbitos de governo e seu aspecto histórico, este último marcado, sobretudo, por sua natureza institucional (SILVA JR; FERRETTI, 2004). Soma-se à consideração a ideia de que a política de ampliação do Ensino Fundamental para nove anos apresenta "um ciclo" até sua chegada na escola, sua concretização e efeitos. Por essa razão, Mainardes (2006) possibilita-nos analisar criticamente, a partir da leitura que faz de diferentes obras de Ball e Bowe (1992, 1998), os contextos de influência, de produção, da prática, de efeitos e de estratégia política. Com os autores, a pesquisa desenvolvida coloca em evidência a

natureza complexa e controversa da política educacional, enfatiza os processos micropolíticos e a ação dos profissionais que lidam com as políticas no nível local e indica a necessidade de se articularem os processos macro e micro na análise de políticas educacionais. (MAINARDES, 2006, p. 49). 
Na perspectiva em destaque, os profissionais da educação não são excluídos, em sua totalidade, dos processos de formulação e concretização da política do Ensino Fundamental de nove anos, o que indica a necessidade de analisar, por um lado, "a formação do discurso da política" e, por outro,

a interpretação ativa que os profissionais que atuam no contexto da prática fazem para relacionar os textos da política à prática. Isso envolve identificar processos de resistência, acomodações, subterfúgios e conformismo dentro e entre as arenas da prática, e o delineamento de conflitos e disparidades entre os discursos nessas arenas. (MAINARDES, 2006, p. 50).

Subsidiando-nos nesses apontamentos, consideramos o que e como os sujeitos integrantes da escola pensam, especificamente, sobre a política em destaque, como tendo implicações diretas no processo pedagógico. E, para analisar suas representações, temos que encontrar outros subsídios teóricos que dêem conta de sua apreensão, porque, conforme Mainardes (2006, p. 58), "ao passo que a abordagem do ciclo de políticas oferece instrumentos analíticos para a análise da trajetória de políticas [...] uma outra teoria mais específica poderia ser empregada para a análise da política ou do programa a ser analisado." (MAINARDES, 2006, p. 58).

Nesse sentido é que nos propomos a analisar as representações sociais dos profissionais da educação das duas escolas públicas (municipal e estadual) sobre a ampliação do Ensino Fundamental de nove anos. Não desconsiderando sua densidade histórica, que traz as marcas das contradições sociais, da função social historicamente posta e também das diretrizes da política educacional, concebemos a escola como espaço institucional de produção do saber historicamente produzido pela humanidade e, também, de atualização histórico-cultural. Tal concepção implica o reconhecimento de uma função pedagógica específica e potencial da escola no enriquecimento da sociedade, do ponto de vista humano, político e social. Apesar de todas as forças contraditórias que possam marcar seu espaço, a escola se constitui como o local institucional de construção humanizadora do ser social e pode servir "à procura por outros horizontes, mais equânimes, mais emancipatórios." (CURY, 2008, p. 220).

Nesse sentido, a compreensão e a análise das representações sociais dos diferentes integrantes sobre as concepções veiculadas pelas políticas educacionais são imprescindíveis, do ponto de vista do nosso referencial teórico-metodológico, por afirmar, entre outros elementos, que as expectativas da comunidade escolar sobre o processo de escolarização acabam por influenciar diretamente na construção de determinadas representações sociais (OLIVEIRA; ARAÚJO, 2005), as quais, por sua vez, ao trazerem funções e dinâmicas sociais próprias, constituem-se como "guia para as ações e trocas cotidianas." (JODELET, 2001, p. 21).

Apesar de considerarmos os contextos explicitados, realizamos exposição do contexto de produção da política educacional em estudo para podermos nos concentrar no contexto da prática, a partir da perspectiva teórica das representações sociais. Para tal fim, dividimos o texto em três partes.

$\mathrm{Na}$ primeira parte, identificamos, mediante síntese descritiva, as principais normas que legalizaram o Ensino Fundamental de nove anos, nos diferentes âmbitos do governo (federal, estadual e municipal, sendo estes dois últimos os das escolas envolvidas), na tentativa de contextualizar os textos políticos que representam, em parte, a política. Destacamos que "os textos políticos são o resultado de disputas e acordos, pois os grupos que atuam dentro dos diferentes lugares da produção de textos competem para controlar as representações da política." (BOWE et al., 1992 apud MAINARDES, 2006, p. 52). Na segunda, desenvolvemos as principais discussões teóricas que subsidiaram a realização da pesquisa, não pretendendo esgotá-las, dada a complexidade de sua constituição e o pouco uso dela pelos pesquisadores em educação, principalmente aqueles da Administração Escolar. Em seguida, na terceira parte, abordamos a análise dos dados propriamente dita, resguardando o anonimato dos sujeitos, escolas e município envolvidos com a pesquisa. Concluímos com alguns aspectos que apontam, além de constatações, alguns questionamentos e desafios para a realização de pesquisas posteriores. Compartilhamos da ideia de que o conhecimento das representações sociais pode proporcionar, na realidade brasileira, a "reflexão de professores e pesquisadores sobre as possibilidades oferecidas por esse campo de estudos para a compreensão dos sistemas simbólicos que, atuando nos níveis grupal e macrossocial, interferem as interações cotidianas na escola, contribuindo para a produção do 'fracasso escolar'." (ALVES-MAZZOTTI, 1994, p. 76).

\section{As diretrizes da política educacional de ampliação do Ensino Fundamental para nove anos nos diferentes âmbitos governamentais}

Vários autores, ao discutirem as direções tomadas pelas políticas educacionais, indicam como um dos principais desafios do atual momento histórico fazer com que o direito à educação "seja, além de garantido e efetivado por meio de medidas de universalização do acesso e da permanência, uma experiência enriquecedora do ponto de vista humano, político e social, e que consubstancie, de 
fato, um projeto de emancipação e inserção social" (OLIVEIRA; ARAÚJO, 2005), a partir, sobretudo, da perspectiva de escola como "espaço institucional de produção e de disseminação, de modo sistemático, do saber historicamente produzido pela humanidade." (DOURADO; OLIVEIRA, 2009).

Alegislação educacional brasileira traz, em seu histórico, leis que permeiam a ampliação do tempo de escolarização obrigatória (BRASIL, 1961, 1971), principalmente a partir da década de 1960, momento em que as políticas educacionais brasileiras passam a ser fortemente influenciadas por políticas de financiamento do setor social pelo Banco Mundial, com interesse em exercer maior controle sobre os países subdesenvolvidos ou em desenvolvimento. Como resultado, a educação brasileira é traçada sob os moldes dos acordos MEC/USAID, que atribuem à administração pública conceitos empresariais como "produção" e "produtividade", traços da nova governabilidade da educação (FAZENDA, 1988; KRAWCZYK, 2008). A partir desse contexto, são desenhadas as políticas educacionais e a legislação que instauram novo modelo de gestão da educação pública, baseado em três princípios: municipalização (descentralização entre as diferentes instâncias de governo), autonomia escolar (descentralização para a escola) e responsabilidade social (descentralização para o mercado). O Estado, assim, propõe-se como um Estado avaliador (KRAWCZYK, 2008).

Franco, Alves e Bonamino (2007) destacam que, ao contrário das descontinuidades políticas ocorridas entre os anos 1970 e 1980, dos anos de 1990 aos dias atuais estamos vivenciando continuidades das diretrizes das políticas educacionais ${ }^{4}$ marcadas pela racionalidade em suas formulações e implementações, tanto naquela que diz respeito aos meios (financiamento, acesso e prioridades) quanto na política substantiva, especificamente relacionada aos resultados de aprendizagem. E, apesar disso, a "magnitude do desafio da qualidade está além do potencial das políticas que circulam entre nós." (FRANCO; ALVES; BONAMINO, 2007, p. 1008). Isso se deve, sobretudo, à necessidade de considerarmos que a prática escolar cotidiana está para além dos aspectos racionais instrumentais e substantivos previstos e cobrados pelas atuais diretrizes.

Não se podem desconsiderar essas questões quando, historicamente, é abordada a ampliação do ensino obrigatório no país. Com a publicação da nova LDBEN (Lei n. 9394/1996) os municípios passam a poder optar por matricular alunos de seis anos no Ensino Fundamental, desde que todas as

\footnotetext{
${ }^{4}$ Neste texto, consideramos políticas "como conjunto relativamente articulado de medidas, relacionadas co $\mathrm{m}$ seu contexto social e político." (FRANCO; ALVES; BONAMINO, 2007).
}

crianças de sete anos estejam matriculadas (artigo 87). Com essa Lei, há a sinalização para a ampliação do Ensino Fundamental obrigatório para nove anos, o que se torna meta progressiva explícita no Plano Nacional de Educação (BRASIL, 1996, 2001).

Em 2005, a Lei Federal $n^{\circ} 11.114$ (BRASIL, 2005) determina a matrícula aos seis anos de idade, legalizando um procedimento administrativo já antecipado pela LDBEN/1996, uma vez que alguns municípios, visando a receber, naquele momento, maiores verbas do FUNDEF ${ }^{5}$, adiantavam-se na implantação de um ensino de nove anos (ALVES, 2006). Entretanto, o Ensino Fundamental de nove anos só é efetivado em 2006, com a Lei Federal $n^{\circ}$ 11.274, que define como obrigatória a matrícula de crianças aos seis anos e estabelece para 2010 o prazo para a efetivação pelos municípios e Distrito Federal (artigo 5) (BRASIL, 2006).

A Secretaria de Educação Básica do Ministério da Educação (SEB/MEC) aborda o assunto em pauta principalmente no documento intitulado Ensino Fundamental de nove anos: orientações gerais (BRASIL, 2004), ao evidenciar alguns dos aspectos políticos e pedagógicos que justificam a ampliação do Ensino Fundamental para nove anos ${ }^{6}$ : indicadores nacionais mostram a não universalização do Ensino Fundamental aliada a uma situação de exploração do trabalho infantil. Ainda, $21,7 \%$ das crianças matriculadas repetem a mesma série e apenas $51 \%$ concluirão o Ensino Fundamental, terminando esse nível de ensino depois de 10,2 anos na escola (BRASIL, 2004).

As Orientações Gerais da SEB/MEC (BRASIL, 2004) defendem que a política de ampliação do Ensino Fundamental garante o aumento do número de crianças incluídas no sistema educacional de forma obrigatória e como direito público subjetivo. Aponta que, em comparação com a rede particular, as crianças que frequentam a escola pública estão em desvantagem, pois aos seis anos a escola particular permite a matrícula no Ensino Fundamental.

O documento aponta a necessidade de uma "mudança na estrutura e na cultura escolar", o que exige "conceber uma nova estrutura de organização dos conteúdos em um Ensino Fundamental de nove anos" (BRASIL, 2004). Exige também, entre outras decisões, a reorganização de tempos, espaços e relações escolares a partir de discussões que avaliem

\footnotetext{
${ }^{5}$ O Fundo de Manutenção e Desenvolvimento do Ensino Fundamental e de Valorização do Magistério (FUNDEF) foi substituído pelo Fundo de Manutenção e Desenvolvimento da Educação Básica e de Valorização dos Profissionais da Educação (FUNDEB) com a Lei $n^{\circ} 11.494$, de 20 de Junho de 2007.

${ }^{6}$ Esse documento é referência nacional para as questões pedagógicas, administrativas e de avaliação no que se refere à ampliação do ensino fundamental para nove anos.
} 
a qualidade do trabalho desenvolvido e, principalmente, a finalidade das rotinas que as escolas adotam. Entre outras características, é frisada a necessidade de uma "gestão participativa, compartilhada e que tenha como referência a elaboração coletiva do projeto político-pedagógico, contemplando a ampliação do Ensino Fundamental”, tendo esta política aliada ao comprometimento com o desenvolvimento dos educandos. Assim, essas reflexões devem (re) construir o trabalho de gestores e educadores e estabelecer novas formas de organização do trabalho pedagógico, que privilegiem, sobretudo, a reorganização de sua estrutura,

[...] as formas de gestão, os ambientes, os espaços, os tempos, os materiais, os conteúdos, as metodologias, os objetivos, o planejamento e a avaliação, de sorte que as crianças se sintam inseridas e acolhidas num ambiente prazeroso e propício à aprendizagem. (BRASIL, 2004).

O Ministério da Educação orienta que as escolas contemplem, em seu projeto político pedagógico, estratégias que contribuam com o desenvolvimento da criança e com as propostas da ampliação. Destaca, enfaticamente, a elaboração coletiva desse projeto, partindo de uma avaliação da escola por parte da sua comunidade, para uma programação de seus objetivos e metas. O projeto político-pedagógico deve assinalar, ainda, os resultados da escola e de seus alunos, mediante, também, indicadores de rendimento. avalia que

Como resultados esperados, a SEB/MEC

a ampliação em mais um ano de estudo deve produzir um salto na qualidade da educação: inclusão de todas as crianças de seis anos, menor vulnerabilidade a situações de risco, permanência na escola, sucesso no aprendizado e aumento da escolaridade dos alunos. (BRASIL, 2004).

$\mathrm{Na}$ leitura crítica das orientações gerais para a implantação da política de ampliação do Ensino Fundamental para nove anos, percebemos movimento contraditório em dois momentos: ao denunciarem a maneira como as escolas organizam seu trabalho pedagógico, não contextualizando essas práticas em espaços maiores de interlocução entre escola pública e políticas governamentais; e ao determinarem a necessidade de transformar a escola pública em um espaço de efetiva construção da cidadania e do acesso ao conhecimento, mas, ao mesmo tempo, não contemplarem nessa transformação aspectos importantes, como a construção da autonomia da escola púbica e a especificidade de cada organização escolar. Considerando as lacunas dos documentos norteadores no que tange à ausência de orientações sobre as ações que preconiza, a concretização do atendimento pedagógico às crianças de seis anos nas escolas de Ensino Fundamental sustenta, em uma face, o descompromisso do Estado com políticas que atendam a Educação Infantil e, na outra, questionamentos sobre as reais origens dessa proposta política (ARELARO, 2005).

As mudanças trazidas com a Lei $n^{\circ} 11.274 / 06$ foram sentidas diretamente pelas administrações estaduais e, principalmente, municipais - as exigências legais impostas pressupõem a reorganização de despesas e do trabalho educativo ${ }^{7}$. O Conselho Estadual de São Paulo manifestou-se via Pareceres, Deliberações, Resoluções e Indicações (SÃO PAULO, 2005, 2006, 2008a, 2008b ${ }^{8}$ ). As considerações estaduais apontam que a política de ampliação não faz sentido em um cenário onde ainda não existem, na grande maioria dos municípios, as cinco horas diárias de permanência na escola. Ainda, argumentam que em Estados como São Paulo a maioria dos municípios já efetivou a universalização da Educação Infantil de zero a sete anos. O Estado traz como implicações para a concretização da política de ampliação quatro questões principais: idade de matrícula, conteúdo pedagógico do primeiro ano, identidade pedagógica do último ano da Educação Infantil/primeiro ano do Ensino Fundamental e divisão de recursos entre estados e municípios.

A Deliberação do CEE n 61/2006 (SÃO PAULO, 2006) fixa as normas para implantação do Ensino Fundamental de nove anos no Estado de São Paulo e determina, entre outros aspectos, as seguintes medidas: reorganização curricular e pedagógica; nova organização dos tempos e redimensionamento dos espaços e ambientes (os quais devem estar mais próximos aos dos dois últimos anos da Educação Infantil); adequação às formas de gestão pedagógica; e formação continuada dos professores para atenderem às especificidades dos novos alunos. Outro aspecto que merece destaque é o da necessidade de a proposta pedagógica articular a Educação Infantil ao Ensino Fundamental, uma vez que se trata de

[...] uma política afirmativa que requer, de todas as escolas e de todos os educadores, compromisso com a elaboração de um novo projeto pedagógico para o Ensino Fundamental, bem como para o conseqüente redimensionamento da Educação Infantil. (SÃO PAULO, 2006).

Outro posicionamento oficial só é emitido em 2008, quando o Estado esclarece questões relativas à idade de ingresso no Ensino Fundamental (crianças que completam seis anos até a data de 30 de junho) e à situação das instituições privadas de ensino, e reafirma a colaboração entre Estados e municípios,

\footnotetext{
${ }^{7} \mathrm{~A}$ maioria das escolas que oferecem ensino fundamental pertence à rede municipal.

${ }^{8}$ Esses documentos constroem as diretrizes estaduais para a implantação da política de ampliação.
} 
apesar de dispor que cabe aos municípios "os ajustes de infra-estrutura e de pessoal necessários à implementação" (SÃO PAULO, 2008b). Em 2009 e 2010, o Estado não publica nenhum documento a respeito da política em questão.

Como a pesquisa que orienta a elaboração do artigo trabalhou com a implantação do Ensino Fundamental de nove anos no município, realizamos o levantamento da legislação que pudesse contribuir com a análise das entrevistas realizadas na escola municipal.

Em entrevista realizada ${ }^{9} \mathrm{com}$ a Secretária de Educação do município por uma das integrantes do grupo de pesquisa ao qual está vinculado este artigo, foi possível detectar que esse município do interior do estado (que a partir deste momento passa a ser designado por AM) adiantou-se, em relação ao Estado, na implantação do Ensino Fundamental de nove anos.

A Lei Orgânica do município (1990) explicita a atribuição de prover o Ensino Fundamental municipalizado e dispõe sobre a ampliação do Ensino Fundamental para nove anos ${ }^{10}$. Em 2009, a Secretaria Municipal de Educação divulgou uma Proposta Curricular para $01^{\circ}$ ano do Ensino Fundamental, com o objetivo de "subsidiar o fazer pedagógico de cada professor e garantir uma unidade de ação em nível de Secretaria Municipal da Educação." (PCM, 2009) ${ }^{11}$. O documento, de caráter essencialmente curricular, aponta que o objetivo principal de ampliação do Ensino Fundamental é "assegurar a todas as crianças um tempo mais longo de convívio escolar com maiores oportunidades de aprendizagem" (PCM, 2009), não atribuindo destaque ao aspecto organizacional.

Do exposto, em termos legais, destacamos que a política de ampliação do Ensino Fundamental para nove anos insere-se em um modelo de gestão educacional pública em que o Estado deposita uma relativa autonomia aos municípios e às escolas para executarem políticas que propõem uma transformação dos tempos e espaços escolares, em favor da melhoria da qualidade do ensino. O município pesquisado, por sua vez, padroniza as escolas através do currículo e do controle da gestão e repassa orientações tradicionais para a organização do trabalho pedagógico e administrativo. Não podemos esquecer que, paralelamente à legislação em pauta, são colocadas em prática inúmeras formas de avaliação em larga escala que acabam por imprimir à escola

\footnotetext{
${ }^{9}$ Processo 2009/15537-4.

${ }^{10}$ Art. 199 O dever do Município com a educação será efetivado mediante a garantia de: I - ensino fundamental, obrigatório e gratuito, com duração de nove anos, iniciando-se aos seis anos de idade (AM, 1990).

${ }^{11}$ Conforme anunciamos, a referência ao município será omitida.
}

uma forma de organização do trabalho pedagógico talvez conflitante com as determinações apresentadas, principalmente no que se refere à necessidade de reorganização de tempos e espaços e nova gestão pedagógica. Apesar de não serem nosso foco de atenção, esses aspectos se fizeram presentes nos momentos de nossas entrevistas, quando pudemos tensionar dados legais com as referências teóricas e a realidade escolar.

Destacamos, ainda, que a legislação que orienta as escolas quanto às transformações esperadas da gestão da escola não discute pontos importantes como a organização coletiva de um projeto político-pedagógico que defina, primeiramente, o que se compreende como qualidade de ensino para a escola pública.

Esse breve mapeamento contribuiu para estarmos coerentes com o consenso, entre os diferentes pesquisadores da área, de que as representações sociais precisam ser apreendidas no contexto das condições de sua produção (SPINK, 1993; MOSCOVICI, 1978; ALVES-MAZZOTTI, 1994). Certamente, não conseguimos contemplar a complexidade das condições de produção, mas, no limite, evidenciamos as diretrizes gerais dos textos da política.

\section{As representações sociais dos profissionais da educação no cotidiano escolar ${ }^{12}$}

A pesquisa analisou entrevistas realizadas com integrantes da equipe gestora e da equipe de docentes do primeiro ao quinto ano do Ensino Fundamental de duas escolas públicas do município, sendo uma estadual e outra municipal, guardada a semelhança de altos resultados no IDEB. As falas das entrevistadas, contempladas em sua totalidade, expressam como cada grupo (da escola estadual e da escola municipal) representa a política de ampliação do Ensino Fundamental para nove anos e quais as transformações administrativas e pedagógicas realizadas em função dessa política. Priorizamos a análise das entrevistas sob três temas: 1 . Representações sobre a política de ampliação do Ensino Fundamental para nove anos; 2 . Representações sobre a função da gestão no processo de implementação; 3. Organização do trabalho na escola fundamental de nove anos.

Sá (1998) indica que a educação é a quarta área que produz pesquisas em representações

\footnotetext{
${ }^{12}$ Neste item, trabalharemos com os profissionais entrevistados e assim os designaremos: diretora da escola municipal (DEM); diretora da escola estadual (DEE); professor 1 da escola municipal (PEM1); professor 1 da escola estadual (PEE1) e assim sucessivamente.
} 
sociais. Ao identificar os principais temas dos estudos, percebemos, claramente, a ausência de pesquisas em Política e Administração da Educação. Somam-se à afirmação desse autor algumas pesquisas da área citada que, ao contemplarem os assuntos mais atuais e complexos - como a qualidade da educação escolar -, indicam a necessidade de desenvolvimento de pesquisas sobre cultura organizacional e representações sociais que consigam abranger as expectativas e demandas da comunidade escolar (DOURADO; OLIVEIRA, 2009; OLIVEIRA; ARAÚJO, 2005). Nesse sentido, debruçamo-nos nos estudos sobre autores clássicos que pudessem contribuir com a leitura de nossos dados empíricos (MOSCOVICI, 1978; JODELET, 2001).

Devido aos limites do texto, apresentaremos alguns aspectos que nortearam as análises e conclusões da pesquisa, iniciando pelo entendimento das representações sociais como "fenômenos complexos sempre ativados e em ação na vida social". Elas são assim entendidas porque se constituem como uma "forma de conhecimento, socialmente elaborada e partilhada, com um objetivo prático e que contribui para a construção de uma realidade comum a um conjunto social." (JODELET, 2001, p. 21). Apesar de serem consideradas como saberes do senso comum, as representações sociais são objeto de estudo tão legítimo quanto os saberes científicos, devido, sobretudo, a sua importância na vida social e na "elucidação possibilitadora dos processos cognitivos e das interações sociais." (JODELET, 2001 , p. 22). Consideramos que a forma como os diferentes integrantes das escolas se apropriam das informações, discussões e conhecimentos referentes à política de ampliação do Ensino Fundamental de nove anos e os representam repercute em suas condutas e na maneira de organização do trabalho na escola, ou seja, no fazer política no cotidiano escolar. Ao possibilitar-nos a análise integrada de processos individuais e sociais e, sobretudo, organizacionais, indicamos a importância de conhecê-los.

Concordamos com Jodelet, quando afirma que as representações sociais

orientam e organizam as condutas e as comunicações sociais, [...] intervêm em processos variados, tais como [...] o desenvolvimento individual e coletivo, a definição das identidades pessoais e sociais, a expressão dos grupos e as transformações sociais e, por isto, o estudo se constrói ao abordá-las do ponto de vista do produto e do processo, respectivamente, 'uma modalidade de pensamento, sob seu aspecto constituinte' e 'constituído, os produtos ou conteúdos'. (JODELET, 2001, p. 22).

Ao evidenciar as problemáticas das representações sociais que são objeto de trabalhos teóricos e empíricos, Jodelet (2001) indica: condições de produção e de circulação; processos e estados (o conteúdo das representações sociais); estatuto epistemológico das representações sociais. Neste texto, procuramos desenvolver algumas condições de produção e de circulação das representações sociais ao analisarmos, anteriormente, as principais diretrizes da política educacional e as contradições implicadas em sua construção e, sequencialmente, ao trabalharmos com os processos e estados a partir da análise do conteúdo das entrevistas realizadas nas duas escolas públicas. Do ponto de vista do ciclo de políticas explicitado em momento anterior, isso significa trabalharmos com os contextos de influência, de produção e da prática (MAINARDES, 2006), sendo este último apreendido a partir das representações sociais dos sujeitos que vivenciam a prática escolar.

$\mathrm{Na}$ perspectiva identificada, está presente a relação dialética entre a natureza individual e a natureza social; o sujeito reconstrói o objeto representado ao interagir com o mundo externo, o que possibilita a ele inserir-se também nesse universo social. A relação se faz quando os aspectos sociais interferem nas elaborações das representações individuais e estas, por sua vez, interferem diretamente na interação social. Considerando esses aspectos, principalmente a relação dialética entre a natureza individual e a natureza social e os elementos contextuais presentes no momento de elaboração da representação, analisaremos as falas dos docentes e gestores entrevistados sobre os temas identificados anteriormente.

Outro ponto que precisamos esclarecer é que, para interpretar as representações sobre os temas, recorremos à perspectiva histórica da Administração Escolar, que indica, entre outros aspectos, que até a década de 1980 predominou, ao menos teoricamente, a adoção da abordagem empresarial para a análise da escola. Somente a partir de meados dessa década, houve o crescimento de pesquisas que afirmam a especificidade da escola e de seu processo de produção pedagógico. Em relação à primeira posição, faremos referência a alguns autores considerados clássicos (RIBEIRO, 1968; ALONSO, 1976); para abordarmos a segunda posição, optamos por trabalhar com a perspectiva de Paro (1986), que, de certa forma, representa e impulsiona os estudos com esses subsídios teóricos. Para nós, a primeira posição revela certa postura conservadora, dos pontos de vista teórico e prático; e a segunda indica posicionamento progressista, mas ainda em elaboração, do ponto de vista teórico, e posicionamento não vivenciado, do ponto de vista prático.

Nosso duplo desafio é procurar responder, por um lado, como e em que medida o social interfere na elaboração individual dos entrevistados e esta interfere no social; e, por outro, se é possível 
caracterizar, distinguir e aproximar os dois grupos estudados, o da escola municipal e o da escola estadual. Em outras palavras, procuraremos, no limite, compreender como as representações sociais construídas pelos dois grupos repercutem na implementação da política educacional de ampliação do Ensino Fundamental para nove anos.

\section{A política de ampliação do Ensino Fundamental de nove anos}

Os profissionais entrevistados nas duas escolas concordam que o primeiro ano do Ensino Fundamental de nove anos é uma adaptação do pré III e da antiga primeira série. Nas duas escolas, os profissionais entendem que é uma política que "veio mais para estar sanando a questão de tanta criança que não estava dentro da escola" (DEM, 2010). Porém, para a DEE, não foi uma política vantajosa, pois a estrutura das escolas municipais é boa e elas trabalham melhor as especificidades da Educação Infantil, o que exigiu algumas apropriações e reformulações por parte das escolas estaduais. Antecipar o acesso ao Ensino Fundamental implica matricular aos seis anos crianças que antes recebiam um atendimento educacional específico nas escolas municipais de Educação Infantil (EMEls).

Os documentos legais, conforme apontamos, indicam a necessidade de redimensionamento entre a Educação Infantil e o Ensino Fundamental, e a consequente reorganização do trabalho no Ensino Fundamental. As duas escolas, no entanto, diferenciam-se quanto às concepções que norteiam essa reorganização, implicando outras concepções do trabalho pedagógico com o primeiro ano. Os profissionais da escola estadual apontam relativa abertura a mudanças estruturais e pedagógicas e trazem a preocupação em trabalhar com todos os aspectos do desenvolvimento da criança, não enfatizando a alfabetização no primeiro ano. $O$ trabalho com a criança de seis anos exigiu da escola estadual também a mudança nos espaços que iriam atendê-la. Assim, a principal dificuldade para a escola estadual foi a ausência da estrutura física própria para as crianças que ingressaram com seis anos. A DEE diz que parquinhos já foram solicitados para a Diretoria e que os espaços físicos da escola foram alterados em função da entrada das crianças pequenas. A integrante da equipe de gestão, que - pelo que foi diagnosticado nas observações efetuadas diária e cotidianamente durante a realização da pesquisa - é responsável integral pelos aspectos pedagógicos da escola, também enfatiza que precisaram organizar o espaço para os alunos:
[...] fizemos o horário de recreio separado, porque eles são pequenininhos, e uma série de coisas estruturais que eu não me lembro no momento, mas assim, teve toda uma preparação, a parte pedagógica, fizemos um plano para eles, respeitando horário e toda aquela parte de carga curricular, só alfabetização, alguma coisinha de matemática e nada mais. $E$ as coisas que vão aparecendo no dia a dia. (CEE, 2010).

Em movimento contrário, a DEM afirma que foi um ganho para a escola de Ensino Fundamental (EMEF) esse acréscimo de um ano, porque, segundo ela, "já estamos preparando a criança da nossa maneira para eles irem para uma parte de alfabetização no segundo ano" e, assim, "eles vão estar entrando no segundo ano acostumados com a política da escola" (DEM, 2010). A profissional afirma que seu espaço não é o de uma escola municipal de Educação Infantil, nele existem regras e uma obrigatoriedade que não existem na EMEI, "continuamos não tendo essa parte de areia, de parque, porque não é do nosso interesse ter isso e, no entanto, eles [os alunos] estão indo bem" (CEM, 2010). Assim, a maior dificuldade da escola municipal está relacionada à indisciplina das crianças, ou melhor, à adequação da criança, ainda com características da Educação Infantil, aos espaços, valores e regras da escola de Ensino Fundamental.

Em relação ao currículo, as profissionais das duas escolas apontam que não houve mudanças significativas nos outros anos do Ensino Fundamental. O primeiro ano da escola estadual passou a ser "um pré III mais direcionado para a alfabetização" (CEE, 2010); já na escola municipal, a coordenadora afirma que não existiram alterações curriculares significativas. As falas das professoras das duas escolas trazem argumentos favoráveis a respeito da política de ampliação do Ensino Fundamental. As professoras estaduais afirmam que as orientações da escola foram para que as crianças não ficassem as cinco horas dentro da sala. A PEE1 é a única profissional que fala sobre as orientações estaduais e indica que sua prática aliou as orientações oficiais às da escola:

[...] assim, eu continuo sendo contra [a política] se as crianças forem ficar dentro de sala de aula, com o currículo igual o da $1^{\text {a }}$ série, agora da forma como veio as orientações eu acho que é legal, eu aprovei, eu só acredito que tenha que ser feito obrigatoriamente e rápido uma adequação na estrutura do prédio, para continuar recebendo essas crianças, porque o professor ficar fazendo adequações, arrumando daqui, arrumando dali para conseguir desenvolver alguma coisa é ruim e prejudica o aprendizado. Se elas tiverem um espaço próprio para fazer determinada atividade, isso vai ajudar muito no desenvolvimento da criança (PEE1, 2010). 
$\mathrm{Na}$ escola municipal, em todas as falas das professoras, encontramos ênfase nos elementos da organização do trabalho na escola. Para elas, o funcionamento pedagógico depende do cumprimento das normas regimentares e disciplinares. Sendo assim, as dificuldades encontradas com a entrada das crianças de seis anos foram em razão da "imaturidade" para acompanharem o "ritmo" da EMEF. "Ah, eles cansam. Eles são imaturos. São crianças. Não podemos esquecer disso" (PEM1, 2010). O trabalho desenvolvido priorizou o preparo dessas crianças para a convivência no cotidiano escolar. Todas as professoras afirmam que o trabalho com a alfabetização já no primeiro ano é um ganho para a escola no sentido de "adiantar" o que seria, muitas vezes, um problema para a professora da antiga primeira série. A alfabetização é entendida, de modo geral, como a decodificação de letras, sílabas e palavras.

A ausência de uma proposta pedagógica clara a favor da melhoria concreta da qualidade do ensino compromete o trabalho com a construção de um novo Ensino Fundamental, que atenda crianças a partir dos seis anos (DURAN, 2006). Falta, pois, a consciência de que a escola tem por principal função a atividade de aprendizagem. Sem a consolidação teórica e prática de tal objetivo, a escola e suas políticas de inclusão caem no viés da prática compensatória, que pouco acrescenta ao desenvolvimento intelectual do aluno. Alves (2006), ao defender que a ampliação do tempo de escolarização é só um direito válido se efetivar a formação de um sujeito participativo em sua sociedade, analisa que aumentar o tempo de permanência na escola não efetiva uma melhoria na qualidade de ensino, se esse ensino de nove anos não criar, de fato,

[...] condições objetivas para que todas as crianças da escola se integrem ao mundo letrado, tornando-se efetivamente usuárias da leitura e da escrita; incorporem o ethos cultural usufruindo e produzindo arte e conhecimento, não com o argumento genérico de que ler traz mais cultura e cidadania, como se isso bastasse para melhorar a vida das pessoas, mas entendendo que isto é indispensável para a conquista da cidadania e a construção de um mundo melhor. (ALVES, 2006, p. 5).

Previamente, a proposta de um Ensino Fundamental de nove anos é uma tentativa de se alterar as rotinas da escola, o que "[...] já significa romper com as formas tradicionais de organização da escola, já significa alterar a estrutura da escola, pois isto implica trazer à tona a dicotomia entre Ensino Fundamental e a Educação Infantil" (DURAN, 2006, p. 7). Mas essa proposta deve influenciar mudanças curriculares que garantam o uso social do conhecimento para a transformação pessoal e social, o que resultaria em uma efetiva aprendizagem e, consequentemente, na continuidade dos estudos.
Sendo assim, a antecipação do acesso ao Ensino Fundamental deve acompanhar uma nova maneira de organizar o ensino, uma vez que "[...] o ensino fundamental de nove anos se ancora numa outra organização da escola: mais aberta, mais flexível, mais participativa, mais desafiadora e criativa." (DURAN, 2006, p. 11).

Afinal, ficando apenas na materialização das suas adequações físicas, como supracitado, sem discutir os aspectos pedagógicos que alicerçam a proposta de ampliação do Ensino Fundamental, as escolas não concretizaram ações de planejamento e construção de diretrizes teóricas que norteiem o atendimento integral da criança de seis anos em seus aspectos físico, psicológico, intelectual e social. Além disso, não foram propostas metas para a expansão desse atendimento, com garantia de qualidade, durante os nove anos de Ensino Fundamental.

\section{Organização do trabalho na escola fundamental de nove anos}

As duas unidades escolares trazem os mesmos elementos balizadores da organização do trabalho na escola - divisão de tarefas entre a equipe gestora e qualidade de ensino baseada nos resultados das avaliações externas -, sendo que a função da escola limita-se a atingir esses índices. Sobre o alto resultado nas avaliações externas, as profissionais das duas escolas apontam que é resultado do comprometimento da equipe gestora. Assim, o sucesso da escola é resultado de um gerenciamento que dá conta de lidar com os diversos segmentos e com as determinações e avaliações feitas pelas instâncias do governo. Para as entrevistadas das duas escolas, outros fatores que influenciam nos resultados expressos de "qualidade de ensino" são: participação financeira e pedagógica dos pais e comprometimento dos professores. A escola estadual aponta a participação dos pais no acompanhamento pedagógico dos filhos, mas não no sentido da tomada de decisões administrativas da escola. O mesmo acontece com os professores, que são chamados e ouvidos para algumas decisões pedagógicas, no entanto as administrativas ficam por conta da diretora. "[...] sempre que tem algum aviso, é de questões mais burocráticas, é colocado para a gente, a gente opina e resolve em reunião" (PEE1, 2010, grifo nosso). O cenário não muda na escola municipal, onde a figura da diretora recebe ainda maior destaque. Além do controle administrativo, a diretora responsabiliza-se pelo controle pedagógico.

Nós estamos no portão da escola, de manhã, nós estamos no portão de entrada, na hora do almoço, 
nós estamos no portão da entrada na hora da saída, então os pais entregam nas nossas mãos e nós entregamos nas mãos dos pais, acho que isso faz uma diferença muito grande, porque o pai sabe quem é que está tomando conta da escola, ele sabe que está entregando o filho para uma diretora no portão [...] (DEM, 2010).

Essa e outras falas da DEM e das outras profissionais da escola municipal evidenciam um papel central da diretora na organização do trabalho na escola e na definição das normas regimentais: organização e disciplina. A diretora enfatiza que

[os alunos] foram entrando no ritmo, eles foram entrando no ritmo, sempre, sempre na fila. As brincadeiras bem calmas, nada de agitação, gritaria e alvoroço, sempre aquele ritmo: sai da sala e antes de ir para o refeitório passa, lava as mãos, entra na fila, vai para o refeitório, toma o lanche, todo mundo sentado, terminou de tomar lanche, sai com as estagiárias, cada estagiária fica com uma turma e ai faz a atividade direcionada sentadinho, mais calmo, sabe, atividade mais tranqüila para eles não voltarem agitados para a sala. Então isso é, acho que é um diferencial das outras escolas, em que as crianças normalmente tomam o lanche e já sai correndo, vai brincar, vai para o pátio e fica livre. Eles aproveitam nessas horas livres, normalmente é bola e aí sempre sai uma confusão. Aqui não. Aqui dificilmente uma criança sai machucada, dificilmente uma criança cai, normalmente aqui é bem tranquilo, então é um ritmo assim: todo mundo trabalha em silêncio, todo mundo trabalha tranquilo, nada muito agitado. (PEM4, 2010).

Não existiu um estudo especifico das escolas para a implantação da política de ampliação do Ensino Fundamental para nove anos, o trabalho foi direcionado pelas orientações do governo estadual e municipal. No entanto, a escola estadual relata que "a rede não deu muito suporte para se implantar um ambiente físico e adequado para uma criança de seis anos, que não pode ficar, que todo mundo sabe que não é adequado ficar o período todo naquele período, naquela sala de aula" (DEE, 2010). $\mathrm{E}$ a escola municipal afirma que "teve um curso, foi até nessa escola, com todas as professoras, que deu uma preparação, uma base. Só que na realidade, quando você se depara com a realidade poucas coisas se aproveitavam, foi mais um trabalho assim da coordenação e nosso, assim, de procurar [...]" (PEM1, 2010).

As falas das entrevistadas mostram que a organização da escola estadual para a concretização do Ensino Fundamental de nove anos focalizou os aspectos físicos e materiais e, em um segundo plano, os aspectos pedagógicos, que apresentam resultados ambíguos: por um lado, a antecipação da alfabetização com resultados positivos, ora por se equiparar à escola particular, ora por facilitar o trabaIho a ser desenvolvido nas séries seguintes; e, por outro lado, a incerteza do trabalho pedagógico que abrange o desenvolvimento da criança. A atenção voltou-se para a preparação da criança e não para a preparação de uma nova concepção de criança, de educação e de escola fundamental. Ademais, as percepções das entrevistadas revelam o desconhecimento da proposta do Estado e denunciam a falta de preparação da Diretoria de ensino responsável pela unidade, fatores que influenciam diretamente na organização do trabalho na escola em função da implementação da referida política.

As entrevistas realizadas na escola municipal mostram uma maior atenção da Secretaria Municipal de Educação do que o percebido na escola estadual em relação às orientações da Diretoria Estadual. Além de contar com os documentos nacionais e estaduais, a escola municipal contou com uma proposta curricular e cursos da Secretaria Municipal, a qual se mobilizou em formular uma proposta gradativa para a implantação da política educacional a que estamos nos referindo, o que significa que de alguma forma todos os anos do Ensino Fundamental serão modificados. Porém, isso não significa que existiu uma preocupação por parte das escolas ou da Secretaria em reformular ou incentivar a reconstrução coletiva do projeto político pedagógico. Nota-se que esse documento não é referenciado pelas profissionais das duas escolas. Principalmente nas falas das profissionais da escola municipal, encontramos uma antecipação para o primeiro ano das mesmas práticas utilizadas na antiga primeira série. As entrevistas sugerem que a organização do trabalho, em função da implantação do ensino de nove anos na escola municipal pesquisada, priorizou o enquadramento dos pais e das crianças às regras, em detrimento da preparação da escola. Nos dois casos não encontramos um ambiente de transformação compromissado com a elaboração de um novo projeto pedagógico para os nove anos de Ensino Fundamental. Portanto, não observamos possibilidades de vivências da Administração Escolar para a transformação social (PARO, 1986), proposição teórica que marcou uma mudança paradigmática na área nos idos dos anos 1980.

\section{Espaço da gestão na concretização do Ensino Fundamental de nove anos}

A política de ampliação do Ensino Fundamental para nove anos atende a um movimento político educacional que incentiva a participação e a democratização nas escolas mediante processos que aumentam suas responsabilidades e, concomitantemente, exercem um controle de resultados mais rígido. Esse cenário, marcado por contradições entre a lógica economicista e a lógica das conquistas democráticas impressas 
em documentos legais desde fins dos anos 1980 , repercute diretamente no espaço e na função da gestão nas escolas, que se depara com demandas de produtividade e eficácia, denotando vontade política de ocupar espaços democráticos de efetiva participação.

As duas escolas pesquisadas trabalham com a expressão "equipe gestora" e consideram como parte da equipe gestora o diretor, o vice-diretor e o coordenador pedagógico. As entrevistas com os diretores e coordenadores das duas unidades apontam uma organização do trabalho da equipe gestora norteada pela divisão de tarefas, na qual a diretora e a vice-diretora ficam diretamente envolvidas com a parte administrativa e a coordenadora com a parte pedagógica. A coordenadora pedagógica da escola estadual destaca diretamente que: "eu fico mais com a parte pedagógica, de orientação de professor, de olhar semanário, caderno de aluno, elas ficam mais com a parte administrativa mesmo" (CEM, 2010). Mas, apesar da divisão, sua colega de equipe evidencia que "as funções delas se cruzam, assim, acaba uma se envolvendo na função da outra" (DEE, 2010). Essa organização do trabalho na escola - pautada na divisão de tarefas - expressa uma visão de administração que separa os aspectos da gestão/administração dos aspectos pedagógicos. A administração é, assim, entendida como instrumento para alcançar fins já propostos e não passíveis de formulação. Em razão disso, a divisão do trabalho é escolhida por ser o processo para melhor conduzir os grupos humanos que operam em tarefas divididas para alcançar um objetivo comum (RIBEIRO, 1968). Em relação às funções das diretoras, as respostas das entrevistadas da escola estadual aproximam-se de uma concepção próxima a de Alonso (1976), que constrói suas ideias com base na teoria sistêmica. Para essa autora, cabe ao diretor de escola:

1 Planejamento e coordenação de programas de relações públicas;

2 Manutenção de regimentos do pessoal escolar;

3 Coordenação de atividades e recursos didáticos para a aprendizagem;

4 Supervisão do pessoal profissional;

5 Aquisição de suprimento e equipamento necessário. (ALONSO, 1976, p. 131).

$\mathrm{Na}$ escola municipal, a organização do trabalho está centrada na figura do diretor, na direção, o que, de certa forma, também é coerente com a autora indicada quando diz que essa função "[...] representa um ponto muito importante uma vez que dela depende o funcionamento da engrenagem administrativa prevista nas fases anteriores do processo, dela dependendo, portanto, o funcionamento da empresa." (ALONSO, 1976, p. 161). As entrevistadas relatam que a diretora está presente em todas as instâncias de trabalho da escola, desde receber as crianças no portão até olhar semanários das professoras, conversar com os pais e resolver os assuntos mais burocráticos. $O$ diretor "desencadeia um processo de trabalho ininterrupto em que todos conhecem a sua participação e aceitam-na." (ALONSO, 1976, p. 170).

$\mathrm{Na}$ escola estadual, a DEE diz que "delega" as funções e, embora não existam indícios de que as decisões administrativas são tomadas coletivamente, a fala das entrevistadas mostra que existem momentos de decisões coletivas, principalmente em relação ao planejamento pedagógico e às pequenas decisões do cotidiano, o que ilustra, talvez, uma ideia de participação por parte das demais profissionais. A fala das duas diretoras mostra que, apesar do diálogo entre os agentes escolares e a comunidade de pais, não existe administração democrática e nem um movimento de construção coletiva da identidade da escola. Na escola municipal, principalmente, esse movimento é anulado, os lemas da escola já estão definidos: "A comunidade escolar tem que entender que nosso lema aqui é disciplina e organização". (DEM, 2010).

As escolas pesquisadas não vivenciam um processo de tomada de decisão coletiva, diminuindo assim as potencialidades da escola pública. Nota-se, também, que as entrevistadas não se preocuparam em definir funções para a escola pública que fossem além de atingir os resultados de qualidade expressa. As duas escolas explicitam uma concepção de qualidade de ensino embasada unicamente nas avaliações externas:

Ano passado nós ficamos em primeiro lugar do município, do índice, e também no Estado de São Paulo, e no Brasil, na cidade. Então a gente tem um índice alto a ser atendido porque a gente ainda vive, tá vivendo sob esse negócio de metas, estamos trabalhando para isso, e eu acho que o nosso maior êxito é esse, é o resultado (CEE, 2010).

A partir do momento em que nós entramos em acordo nisso, todo mundo se uniu e os pais entenderam, a comunidade escolar entendeu, tem que virar obrigatoriamente uma escola de qualidade (DEM, 2010).

Por outro lado, temos na fala da CEE uma contradição entre a carga de responsabilidade e o limite de ação:

Isso hoje a gente tem, a gente trabalha sob índice e é tudo em cima da hora, então essa parte burocrática e da instituição mesmo que tá acontecendo agora ainda tá meio desestruturada, então você tem que fazer tudo às pressas. Então do mesmo jeito que para mim é complicado, eu acabo apressando meu professor, e quando você vê gera um pouco de desconforto, de tensão, mas eu acho que isso é em toda escola [...] (CEE, 2010). 
Talvez por terem atingido altos índices, as entrevistadas afirmam que a escola não enfrenta grande dificuldade - a dificuldade é de os alunos acompanharem o ritmo de trabalho:

Olha... maior problema não tem. Você fala assim, é... existem problemas que acontecem em todas as escolas, um aluno ou outro que não, que tem problema de aprendizagem e que você tem que correr atrás e convocar pai, "vamos lá", vê a tarefa, tem que por um pouquinho mais pra estudar, e vamos por na aula de reforço, porque a gente oferece (CEE, 2010).

[a maior dificuldade] foi mais a questão da disciplina das crianças, a questão de comportamento, eles não estavam acostumados, e aqui, eles ficam cinco horas, na EMEI não, eles ficavam quatro horas, eles não estavam acostumados com isso (CEM, 2010).

Percebemos na fala das gestoras que elas desconhecem a estrutura legal que embasa a política de ampliação. Além disso, as escolas não discutiram a proposta antes de implantá-la, o que sugere que não existe autonomia dos profissionais para discutirem sobre as decisões impostas pelo governo, autonomia essa compreendida não apenas como a concessão de espaço, mas como conquista e construção coletiva do poder de tomada de decisão. As entrevistadas não apresentam ideia construída coletivamente sobre as razões da política em questão. Quando questionadas sobre isso, cada uma direciona sua resposta para aspectos diferentes: econômicos, políticos, de antecipação de disciplina, entre outros. Uma das professoras da escola estadual afirma o seguinte:

Eu acho que deve ter uma questão que vem da municipalização do ensino, a Prefeitura não dando conta de toda a demanda, então o Governo aumentou, deve ter alguma coisa aí mais financeira, administrativa, do que de educação, de rendimento e de melhoria da educação, como falam. (PEE1, 2010).

Para as entrevistadas, a gestão influencia sobremaneira o trabalho desenvolvido na escola. Em algumas respostas, temos que a gestão é que determina o funcionamento da escola. A qualidade da escola, portanto, é resultado do perfil da equipe gestora. Porém, mesmo com essa resposta, as professoras não souberam dizer qual é a responsabilidade, a "tarefa" da diretora na organização do trabalho na escola e na implantação do Ensino Fundamental de nove anos. Tivemos a informação de que as diretoras das duas escolas movimentaram-se principalmente em torno da preparação do espaço, sobretudo na escola estadual:

A diretora, a participação da direção foi o espaço ali, com as mesas, de estruturar que mesas iam ficar, fechar o espaço das crianças para que elas tivessem um espaço só para elas, onde os grandes não iriam entrar para atrapalhar, para passar, levar a estante para lá para que a gente disponibilizasse os livros à altura das crianças. (PEE1, 2010).

A PEM2 diz que a função do diretor é "organizar a escola, manter a equipe pedagógica unida, sempre buscando atualizar a todos" (PEM2, 2010), a PEM1 fala que a diretora "é a cabeça" (PEM1, 2010) e a CEE afirma que a diretora "gerencia tudo" (CEE, 2010). Em nenhuma resposta encontramos pistas de que a diretora poderia estar a serviço da construção do trabalho coletivo na escola; ou, no caso da implantação da proposta, que a diretora seria responsável por incentivar a busca e reflexão coletiva para uma formação continuada.

A fala dos entrevistados sobre a função dos diretores enquanto "gerenciadores" do trabalho da escola está situada em um momento histórico no qual o cargo de diretor é "[...] a principal carreira em que se dá a incorporação do novo gerencialismo, sendo crucial para a transformação dos regimes organizacionais das escolas" (BALL, 2006, p. 13). Assim, depende do comprometimento e da competência do diretor o envolvimento da comunidade pela aprendizagem dos alunos. Essa postura também é compartilhada pela DEM, que afirma que a aprendizagem dos alunos e a qualidade da escola só são possíveis se toda a comunidade entender os propósitos da escola.

Apesar de a proposta do governo (BRASIL, 2004) trabalhar com a necessidade de a escola reorganizar as formas de gestão, o que obtivemos, a partir das falas das entrevistas, é uma administração centralizada na equipe gestora, que repassa as informações pedagógicas às professoras. Também, nesse cenário, são excluídas as chances de participação dos pais nas decisões da escola. As diretrizes oficiais que regem a política do Ensino Fundamental de nove anos foram formuladas sem o conhecimento do cotidiano da escola. Ademais, seus resultados mostram que os discursos oficiais que responsabilizam a escola por promover a participação e a administração democrática são vazios de iniciativas que efetivamente viabilizem esse trabalho. Como pano de fundo, ainda, as escolas e seus gestores continuam a centralizar a organização do trabalho na escola, para que sejam atingidos os objetivos postos fora e acima dela (RIBEIRO, 1968; ALONSO, 1976). 


\section{Considerações finais: entre os discursos da política, as formulações teóricas e as realidades da gestão da escola pública}

Nosso objetivo foi o de apreender as representações sociais de dois grupos de profissionais de escola estadual e escola municipal - docentes e equipe de gestão - sobre a política de ampliação do Ensino Fundamental para nove anos, considerando, sobretudo, que a escola constitui-se em potencial objeto de estudo e sujeito de contribuição para perspectivarmos outra lógica social, com a presença de sujeitos ativos e participativos em sua construção. Consideramos que a política educacional apresenta um ciclo que vai de sua formulação aos seus efeitos na prática escolar, sem que suas fases constituam-se como algo estanque e linear. Com esse referencial e os subsídios teóricos das representações sociais, pudemos analisar as concepções dos dois grupos sobre a política, com foco na organização do trabalho na escola de nove anos e a função da gestão escolar em sua implementação.

Para a análise da gestão, tomamos como referência nossos estudos, no grupo de pesquisa, que abordam autores considerados clássicos da Administração Escolar e que, de certa forma, apresentam perspectivas diferenciadas sobre o assunto. No que tange à política propriamente dita, os documentos dos diferentes âmbitos, principalmente federal e estadual, enfatizam a necessidade de (re)construção do projeto político-pedagógico pelas escolas, no sentido de contemplarem e vivenciarem uma nova escola, agora com o ingresso de crianças de seis anos. Entretanto, a política, tanto no discurso quanto na prática, não veio acompanhada de alterações imprescindíveis para que isso ocorresse; ao contrário, concomitantemente, vem impondo padrões de qualidade com avaliações externas que, de certa forma, determinam currículos e práticas pedagógicas.

Os sujeitos entrevistados, dos dois grupos, atribuem características positivas à política, porém não construíram as bases que a sustentam, ou seja, não a estudaram, não conhecem as raízes de sua constituição e as razões que a fundamentam. Nesse sentido, podemos dizer que as práticas escolares históricas, de centralização de decisões e medidas tomadas hierárquica e linearmente, predominam e influenciam significativamente a elaboração das representações sociais dos profissionais. Ou seja, para eles, se o governo formulou foi para que meIhorasse a qualidade do ensino; assim concebem e concretizam, sem problematizarem, refletirem ou modificarem a forma de organização do trabalho pedagógico em suas escolas.

Nos dois grupos, a função do gestor é de gerente e responsável único pela escola, o que indica ser ainda predominante, na prática, a literatura considerada conservadora da Administração Escolar, ao aproximar o diretor de escola do gerente da fábrica. Enfim, não houve alterações na escola para que pudesse ser considerada de nove anos, houve apenas alguns rearranjos, principalmente físicos, para antecipar a alfabetização e a maturidade (se é que isso é possível) da criança para sua inserção na primeira série, atualmente, primeiro ano.

Em termos de possíveis distinções entre os grupos, notamos que na escola estadual houve maior preocupação com a chegada das crianças e as necessárias adaptações, o que pode indicar margem de autonomia para as práticas profissionais. Essa nossa pressuposição se baseia no fato de que, nas falas, estiveram presentes indícios de que naquela escola foram tomadas algumas providências, o que não significa medidas comuns para as escolas da rede estadual.

Pensando em um dos desafios propostos pelos estudos em representações sociais, o de apreender a relação dialética entre o individual e o social, podemos dizer que as representações individuais que caracterizam cada um dos grupos são fortemente influenciadas pelas marcas históricas da escola enquanto instituição centralizadora e que separa a formulação da execução. Nessa perspectiva, a função dos diretores é exatamente transpor, didaticamente, o texto das políticas aos seus professores para que as executem, e é essa representação que predomina na fala dos entrevistados.

Se considerarmos o texto da política, podemos destacar alguns aspectos considerados progressistas. Entretanto, as contradições emanadas das diretrizes governamentais que incentivam o alcance de metas e benefícios individuais acabam por incentivar as práticas historicamente vivenciadas e não promovem o pensar coletivo e a (re) construção da organização do trabalho na escola.

Finalmente, esperamos ter contribuído com as reflexões que priorizam as representações sociais dos sujeitos da escola, uma vez que, ao apreendê-las, explicitamos as inter-relações entre as naturezas individual e social e compreendemos os motivos pelos quais a escola pública vem reproduzindo suas tradicionais práticas pedagógicas. A análise também proporcionou elementos que indicam potencial contribuição do estudo em representações sociais na Administração Escolar, porquanto, ao compreendermos as expectativas da comunidade e as vivências instauradas a partir das diretrizes da política educacional, podemos vislumbrar novos caminhos permeados por práticas escolares democráticas, condizentes com a mudança paradigmática que marcou, teoricamente, a área na década de 1980. 


\section{Referências}

ALONSO, M. O papel do diretor na administração escolar. São Paulo: Difel, 1976.

ALVES, M. L. A escola de nove anos: integrando as potencialidades da Educação Infantil e do Ensino Fundamental, 2006. Disponível em: <http://www. multimeios.ufc.br/artigos.php>. Acesso em: 03 out. 2007.

ALVES-MAZZOTTI, A. J. Representações sociais: aspectos teóricos e aplicações à Educação. Em Aberto, Brasília: MEC-INEP, v. 14, n. 61, p. 60-78, jan./ mar. 1994.

ANDRÉ, M. E. D. A. A pesquisa no cotidiano escolar. In: FAZENDA, I. Metodologia da Pesquisa Educacional. São Paulo: Cortez, 2006. p. 35-46.

ARELARO, L. R. G. O Ensino Fundamental no Brasil: avanços, perplexidades e tendências. Educação \& Sociedade, Campinas, v. 26, n. 92, p. 1039-1066, out. 2005. DOI: 10.1590/S0101-73302005000300015

BALL, S. J.; BOWE, R. Subject departments and the "implementation" of National Curriculum policy: an overview of the issues. Journal of Curriculum Studies, London, v. 24, n. 2, p. 97-115, 1992.

BALL, S. Sociologia das políticas educacionais e pesquisa crítico-social: uma revisão pessoal das políticas educacionais e da pesquisa em política educacional. Currículo sem fronteiras, v. 6, n. 2, p. 10-32, jul./dez. 2006.

BARROSO, J. (Org.). 0 estudo da escola. Portugal: Porto Editora, 1996.

BRASIL. Lei n. 4024/1961 de 20 de dezembro de 1961. Estabelece as diretrizes e bases da educação nacional. Disponível em: <http://portal.mec.gov.br/ arquivos/pdf/ldben.pdf $>$. Acesso em: 04 ago. 2010.

Lei n. 5692/1971 de 10 de agosto de 1971. Fixa as diretrizes e bases para o ensino de $1^{\circ}$ e $2^{\circ}$ graus e dá outras providências. Disponível em: <http:// www. planalto.gov.br/CCIVIL/LEIS/L5692.htm>. Acesso em: 01 ago. 2010.

Lei n. 9394/1996 de 20 de dezembro de 1996. Estabelece as diretrizes e bases da educação nacional. Disponível em: <http:// portal.mec.gov.br/arquivos/pdf/ Idben.pdf>. Acesso em: 01 nov. 2009.

Lei n. 10. 172/ 2001. Estabelece o Plano Nacional de Educação. Disponível em: <http:// portal. mec.gov.br/arquivos/pdf/pne.pdf>. Acesso em: 01 nov. 2009.

Ministério da Educação, Secretaria de Educação Básica, Departamento de Políticas de Educação Infantil e Ensino Fundamental, Coordenação Geral do Ensino Fundamental. Ensino Fundamental de nove anos: orientações gerais. Brasília, 2004.

Lei n. 11.114, de 16 de maio de 2005. Altera os arts. $6,30,32$ e 87 da Lei n. 9.394 de 20 de dezembro de 1996. Publicado no DOU de 17, maio, 2005.
Disponível em: <http://portal.mec.gov.br/cne/arquivos/ pdf/pceb018_05.pdf>. Acesso em 01 nov. 2009.

Lei n. 11.274, de 06 de fevereiro de 2006. Altera os arts. 29, 30, 32 e 87 da Lei n. 9.394 de 20 de dezembro de 1996. Publicado no DOU de 07, fev. 2006. Disponível em: <http://www.planalto.gov.br/ccivil_03/ Ato2004-2006/2006/Lei/L11274.htm>. Acesso em: $0 \overline{3}$ nov. 2009.

CURY, C. R. J. A Educação Escolar, a exclusão e seus destinatários. Educação em Revista, Belo Horizonte, n. 48, p. 205-222, dez. 2008. DOI: 10.1590/S010246982008000200010

DEROUET, J. L. O funcionamento dos estabelecimentos de ensino em França: um objecto de estudo em redefinição. In: BARROSO, J. (Org.). 0 estudo da escola. Lisboa: Porto Editora, 1996. p. 61-85.

DOURADO, L. F.; OLIVEIRA, J. F de. A qualidade da educação: perspectivas e desafios. Caderno Cedes, Campinas, v. 29, n. 78, p. 201-215, maio/ago. 2009. DOI: $10.1590 / S 0101-32622009000200004$

DURAN, C. O Ensino Fundamental de nove anos: argumentando sobre alguns dos seus sentidos. 2006. Disponível em: <http://www.multimeios.ufc.br/artigos. php>. Acesso em: 03 out. 2007.

FAZENDA, I. C. A. Educação no Brasil anos 60. O pacto do silêncio. São Paulo: Loyola, 1988.

FRANCO, C.; ALVES, F.; BONAMINO, A. Qualidade do Ensino Fundamental: políticas, suas possibilidades, seus limites. Educação \& Sociedade, Campinas, v. 28, n. 100 - Especial, p. 989-1014, out. 2007. DOI: 10.1590/S0101-73302007000300017

JODELET, D. Representações sociais: um domínio em expansão. In: JODELET, D. (Org.). As representações sociais. Rio de Janeiro: UERJ, 2001. p. 17-44.

KRAWCZYK, N. Em busca de uma nova governabilidade na educação. In: OLIVEIRA, D. A. (Org.). Política e Gestão da Educação. 2. ed. Belo Horizonte: Autêntica, 2008. p. 61-74.

LEI ORGÂNICA DO MUNICÍPIO. Publicada em 04 de abril de 1990.

LIMA, L. C. A escola como organização educativa: uma abordagem sociológica. 3. ed. São Paulo: Cortez, 1998.

MAINARDES, J. Abordagem do ciclo de políticas: uma contribuição para a análise de políticas educacionais. Educação \& Sociedade, Campinas, v. 27 , n. 94, p. 47-69, jan./abr. 2006. DOI: 10.1590/S010173302006000100003

MOSCOVICl, S. A representação social da psicanálise. Tradução de A. Cabral. Rio de Janeiro: Zahar, 1978.

OLIVEIRA, R. P. de.; ARAÚJO, G. C. Qualidade do ensino: uma nova dimensão da luta pelo direito à educação. Revista Brasileira de Educação, Rio de 
Janeiro, n. 28, p. 5-22, jan./abr. 2005. DOI: 10.1590/

S1413-24782005000100002

PARO, V. H. Administração escolar: introdução crítica. São Paulo: Cortez: Autores Associados, 1986.

PCM. Secretaria Municipal de Educação. Proposta Curricular para o $1^{\circ}$ ano do Ensino Fundamental. 2009.

RIBEIRO, J. Q. Introdução à administração escolar (alguns pontos de vista). In: Administração Escolar: Edição comemorativa do I Simpósio Interamericano de Administração Escolar. Salvador: ANPAE, 1968. p. 1840.

SÁ, C. P. de. A construção do objeto de pesquisa em representações sociais. Rio de Janeiro: Ed UERJ, 1998.

SÃO PAULO. CONSELHO ESTADUAL DA EDUCAÇÃO. Indicação CEE n.52/2005. Diário Oficial do Estado, São Paulo, 11 nov. 2005a.

CONSELHO ESTADUAL DA EDUCAÇÃO. Parecer CEE n.461/2005. Diário Oficial do Estado, São Paulo, 16 dez. 2005b.

CONSELHO ESTADUAL DA EDUCAÇÃO. Deliberação CEE n.61/2006. Diário Oficial do Estado, São Paulo, 01 dez. 2006.

. CONSELHO ESTADUAL DA EDUCAÇÃO. Deliberação CEE n.73/2008. Diário Oficial do Estado, São Paulo, 02 abr. 2008a.

. CONSELHO ESTADUAL DA EDUCAÇÃO. Indicação CEE n.76/2008. Diário Oficial do Estado, São Paulo, 01 out. 2008b.

SILVA JR., J. dos R.; FERRETTI, C. J. O institucional, a organização e a cultura da escola. São Paulo: Xamã, 2004.

SPINK, M. J. O estudo empírico das representações sociais. In: SPINK, M. J. (Org.). O conhecimento no cotidiano: as representações sociais na perspectiva da psicologia social. São Paulo: Brasiliense, 1993. p. 85-108.

Recebido em 14/04/2011

Versão final recebida em 12/08/2011

Aceito em 31/08/2011 